\title{
O DIREITO À SAÚDE NO PARADIGMA DAS PATENTES SOBRE REMÉDIOS E VACINAS CONTRA A COVID-19 E OS IMPACTOS PARA EVENTUAIS FUTURAS PANDEMIAS
}

\author{
Sandra Regina Martini ${ }^{1}$ \\ Theodoro Luís Mallmann de Oliveira ${ }^{2}$ \\ DOI: https://doi.org/10.47306/978-65-88213-03-2.342-356
}

Sumário: 1 Introdução; 2 Da saúde enquanto direito fundamental a ser universalmente garantido; 3 Do direito à saúde e as novas tecnologias no enfrentamento de pandemias; 4 Do princípio da fraternidade como elemento integrador dos povos e nações em meio a graves pandemias; 5 Conclusão; Referências.

\section{Introdução}

A investigação científica em apreço gira em torno da temática atual e excruciante da situação de pandemia verificada a nível mundial perpetrada pela enfermidade infectocontagiosa cognominada COVID-19 (conhecida popularmente como "Coronavírus"), gerando a necessidade do surgimento de uma vasta gama de testes laboratoriais na tentativa de se obter com o máximo de brevidade possível vacinas ou remédios de fato eficazes para a preocupante situação. Trar-se-á à baila a inevitável problemática de se averiguar até que ponto a instituição de patentes sobre eventuais remédios e vacinas sobre esta pandemia poderá trazer sérios percalços no acesso dos cidadãos a uma cura ou prevenção, no panorama do Direito à Saúde e da Fraternidade.

Os objetivos do trabalho ora cogitado foram subdivididos basicamente em três pontos. Inicialmente, buscar-se-á abordar pormenorizadamente a noção do direito fundamental à saúde (preventiva ou curativa) enquanto assunto expoente dentre os Direitos Humanos e que, por conseguinte, urge ser reivindicado e garantido de modo universal para toda a população do globo, inclusive à luz de normas previstas em organismos internacionais, a exemplo da Organização das Nações Unidas, MERCOSUL e União Europeia.

\footnotetext{
${ }^{1}$ Doutora em Evoluzione dei Sistemi Giuridici e Nuovi Diritti pela Università Degli Studi di Lecce (2001), Pósdoutorado em Direito (Roma Tre, 2006) e Políticas Públicas (Univ. de Salerno, 2010). Professora da Uniritter, UFMS (visitante) e PPGD Direito (UFRGS). Contato: srmartinipoa@gmail.com

2 Advogado e Servidor público federal do Ministério da Justiça. Especialista em Direito Processual CivilUniversidade Anhanguera. Pós-graduando em Direito Tributário-UFRGS. Graduado em Direito pela UFC. Graduando em História-UECE. Contato: supertheodoro@gmail.com.
} 
Em sequência, será examinado o Direito à Saúde e o impacto da doença COVID-19 e na perspectiva das novas tecnologias, incluindo a questão da possibilidade da quebra da exclusividade gerada pela concessão de patentes aos laboratórios e indústrias farmacêuticas, em detrimento da dificuldade de acesso dos cidadãos, em função dos preços e da elevada demanda pela respectiva cura e/ou prevenção.

No tópico final, o estudo estará orientado, em meio ao enfrentamento de pandemias atuais e ainda por vir relacionando com relevância de se re-encontrar com a Fraternidade na condição de elemento integrador dos povos e nações de todo o planeta na busca de uma solução para o problema, deixando de lado diferenças políticas, socioeconômicas, culturais e religiosas.

Esta reflexão tratada se justifica não só em razão da atualidade do preocupante tema, mas também por conta da polêmica necessidade de sopesamento dos direitos relacionados com a saúde dos cidadãos em contraposição ao direito de propriedade (industrial), fazendo-se necessária uma pormenorizada discussão crítico construtiva. No que tange à metodologia empregada, o estudo se vale como métodos de abordagem o dedutivo e o dialético. As técnicas de suporte empregadas compreendem a perquirição sistemática da legislação, doutrina, jurisprudência, artigos e periódicos. Serão colacionadas as considerações finais mediante o destaque dos pontos conclusivos, através de um possível diálogo das fontes.

\section{Da saúde enquanto direito fundamental a ser universalmente garantido}

Conforme inequívoca clareza, os Direitos Humanos configuram-se como um conjunto multifacetado de garantias de naipe indeclinável e plurifinalista voltadas para possibilitar uma harmônica convivência humana dentro das ideias de igualdade, liberdade, fraternidade e dignidade, de acordo com as demandas de um dado contexto histórico e espacial. Tais direitos se manifestam das mais variadas formas, ora como direito-pretensão, ora como direitosliberdade, seja como direito-poder, seja enquanto direito-imunidade. A visível ampliação desses direitos verificou-se especialmente a partir da segunda metade do século XX, muito em razão das barbáries da Segunda Guerra Mundial, propiciando o surgimento de um rol de direitos civis, políticos, econômicos, sociais e culturais. Dentre suas fulcrais características podemos elencar a universalidade, não exaustividade, indivisibilidade, imprescritibilidade, inalienabilidade, indisponibilidade e proibição do retrocesso (RAMOS, 2020 pp. 24, 68-75).

Dentre esses direitos à saúde, na condição de direito social, assume papel visivelmente preponderante em relação aos demais, mormente por estar intrinsecamente ligado ao próprio direito à vida e à dignidade da pessoa humana, estando positivado em praticamente todas as 
Constituições democráticas do globo ${ }^{3}$ e que foi paulatinamente construído e moldado no decorrer das complexas vicissitudes da história humana, ganhando crucial destaque com o advento da Revolução Francesa que culminou com o implemento da Declaração dos Direitos do Homem e do Cidadão de 1789 (BARBOSA, 2017).

Dentro dessa perspectiva, na qualidade de direito humano, a saúde tem de abrangência universal, dispondo de tamanha relevância a ponto de vir prevista nos principais diplomas internacionais contemporâneos concernentes aos sistemas globais e regionais de proteção aos Direitos Humanos que se tem conhecimento, tais como: a) Declaração Universal dos Direitos Humanos (art. 25); b) Pacto Internacional sobre Direitos Econômicos, Sociais e Culturais (art. 12); c) Convenção dos Direitos da Criança (art. 25); d) Convenção sobre a eliminação da discriminação racial (art. 5. ${ }^{\circ}$, letra e, IV); e) Convenção sobre o direito dos povos indígenas e tribais em países independentes (art. 25), entre outros (VENTURA, 2010, pp. 91-93).

Corroborando essa noção de que o direito à saúde é tratado como uma questão de abrangência universal, podemos citar a Resolução GMC nº 151/96 do MERCOSUL, tendo por escopo promover a harmonização das legislações dos seus países membros (Brasil, Argentina, Uruguai, Paraguai e, posteriormente, Venezuela) em relação a bens, matérias primas, produtos e serviços de saúde, demonstrando uma manifesta atenção do Mercosul não só para o âmbito comercial e econômico da integração internacional do bloco, mas principalmente com o aspecto social. (BRASIL, 2014). Note-se que o MERCOSUL tem instrumentos jurídicos para pensar uma política integrada no combate às doenças, porém o que observamos é uma ausência de dialogo entre as Nações e, exatamente por isso, a fraternidade retorna como um necessário contratempo. $^{4}$

Embora as legislações nacional e internacional se mostrem significativamente avançadas do ponto de vista formal, não raras vezes na prática as garantias de implementação ao direito à saúde (tanto preventiva como curativa) ainda pecam por virem marcadas pela tônica da defasagem no atendimento, acompanhamento e prevenção, especialmente no que tange a políticas e ações públicas governamentais de nações soberanas da África e América Latina (VENTURA, 2010, pp. 91-93). No caso específico da atual pandemia, não vemos o Bloco

\footnotetext{
${ }^{3}$ A Carta Magna brasileira de 1988 conferiu tamanha importância ao direito fundamental à saúde, que além de prevê-lo logo no início pelo rol dos direitos sociais (art. $6^{\circ}$ ), reservou um tópico exclusivo para ela no capítulo referente à seguridade social (arts. 196 a 200).

4 Também merece destaque a preocupação da União Europeia com a saúde pública a nível regional, na medida em que no ano de 2013, ou seja, bem antes do surgimento da pandemia COVID19, fora proferida a Decisão $n^{\circ}$ 1082/2013/EU por parte do Parlamento Europeu e do Conselho da União Europeia, com vistas a assegurar um elevado padrão de proteção da saúde pública mediante a coordenação de políticas e ações entre seus Estados membros relativamente às denominadas ameaças sanitárias transfronteiriças graves. (UNIÃO EUROPEIA, 2013)
} 
MERCOSUL, tomar ações conjuntas, mais uma vez reforçamos a importância dos pactos, acordos entre os países, em especial no nosso contexto Regional, onde podemos construir "canteiros da fraternidade", o sentido da fraternidade não está na sua presença, mas na sua ausência. Resgatá-la das masmorras da Revolução Francesa torna-se, atualmente, vital.

Cumpre registrar que esses inquietantes imbróglios da defasagem de ações práticas para fomento do direito à saúde têm sido observados de forma alarmante no que diz respeito à pandemia COVID19, cujo surgimento e propagação mundial se deu de forma súbita e meteórica, acarretando nefastos prejuízos na saúde pública de vários países, especialmente naqueles onde a infraestrutura logística e de recursos humanos mostra-se significativamente precária. Tal celeuma traz ao centro dos questionamentos acerca da necessidade de se promover um enfrentamento da doença COVID19 e outras futuras pandemias de forma conjunta e articulada, independente de desavenças entre ideologias políticas, socioeconômicas, culturais e religiosas, seja ente países capitalistas e socialistas, seja entre povos cristãos, muçulmanos, hinduístas ou budistas, dentro da teleologia hermenêutica de que o descaso com a saúde de determinados povos pode significar uma ameaça a todos os outros países num verdadeiro efeito em cadeia, notadamente em um mundo complexo como o atual, onde a velocidade das comunicações e transportes tem crescido vertiginosamente. Por conseguinte, não se mostra suficiente que os diplomas legais declarem ser a saúde direito do cidadão e dever do Estado, mas criar condições para sua efetivação levando-se em conta as disparidades loco-regionais que possuam uma estrutura global, pois o problema da saúde não é territorialmente limitado (MARTINI, 2009).

Em compasso com a crítica realidade da situação de calamidade pela qual passa a saúde pública mundial, e dentro da preocupação com a prevenção e tratamento da doença pandêmica, o Excelso Superior Tribunal de Justiça já tem inclusive recente Jurisprudência emitida no sentido de priorizar o direito à saúde até mesmo para conversão de prisões preventivas em domiciliares em situações de incidência da COVID-19, conforme decisão do eminente Ministro Reynaldo Soares da Fonseca nos autos do Habeas Corpus n ${ }^{\circ}$ 563.142, a qual colacionamos:

\section{“(..)}

No caso, diante do novo contexto fático, entendo que a prisão preventiva do paciente deve ser substituída pela prisão domiciliar.

Primeiro porque ele comprova ser portador de comorbidades que necessitam de acompanhamento constante (diabetes, hipertensão, distúrbio severo do sono com necessidade de utilização de CPAP). Segundo porque o relatório médico de e-STJ fls. 249/250 revela que seu quadro clínico foi agravado no estabelecimento prisional: (...) 
Terceiro porque a declaração pública da situação de pandemia pelo novo coronavírus - Covid-19, no dia 30 de janeiro de 2020, pela Organização Mundial de Saúde, requer a adoção de medidas preventivas de saúde pública para evitar a propagação do vírus.

Quarto porque o paciente se encontra dentro do grupo de risco, nos termos da Recomendação n. 62 do CNJ, de 17 de março de 2020, a qual estabelece medidas preventivas à propagação da infecção pelo novo coronavírus - Covid-19 no âmbito dos sistemas de justiça penal e socioeducativo; o que impõe a necessidade de revisão da sua prisão.

(...)

Assim sendo, reputo legítima a substituição da prisão preventiva do paciente pela prisão domiciliar, sem prejuízo de que sejam eventualmente fixadas outras medidas cautelares constantes no art. 319 do CPP, a critério do Juízo local. (STJ, 2020, online) (grifo nosso)

A decisão do Ministro certifica e reafirma a ideia que a saúde não pode ser vista de forma isolada, quer por razões legais, por se tratar de um direito humano com característica da universalidade previsto nos vários diplomas internacionais retromencionados, quer por motivos fáticos, pois não raras vezes o surgimento de doenças transpassa barreiras geográficas e politicas, fazendo-se necessário a COVID19 e outras futuras pandemias serem encaradas de forma conjunta pelos governos mundiais, evitando-se consequências ainda mais abomináveis. Por conseguinte, o modelo de organização dos Estados contemporâneos traduz uma sensível ampliação da necessidade de debates a nível dos organismos internacionais, globais e regionais em relação à adoção concatenada de medidas no combate de pandemias atuais e futuras, relativizando inclusive o poder discricionário dos Estados da escolha de políticas públicas quando o assunto diz respeito à delicada saúde pública mundial, com o atributo de direito humano universal (VENTURA, 2010, p. 98).

Impende ressaltar, outrossim, que a temática em comento traz inexoravelmente à tona a questão do direito à propriedade industrial ${ }^{5}$ no que diz respeito às patentes sobre remédios e vacinas contra tais pandemias. Nessas hipóteses, muito embora o direito à propriedade também esteja incluído dentro do rol dos direitos humanos, e conquanto seu núcleo essencial não possa ser tolhido, o mesmo deve ser interpretado em consonância com bens maiores, tais como a saúde, vida, dignidade humana e fraternidade (RAMOS, 2020, p.776).

A discussão sobre patentes retorna, especialmente quando tratamos da saúde como um direito humano e, portanto, um bem da própria comunidade ou como bem comum; esta percepção se opõe à mercantilização da saúde, ou melhor, da doença, à privatização do próprio bem (saúde). O bem comum requer um universalismo do direito desde a perspectiva da inclusão

\footnotetext{
${ }^{5}$ RAMOS (2014, pp. 146-154) leciona que propriedade industrial é uma modalidade de direito intelectual do qual as patentes são espécies, estando relacionados à invenção de novas tecnologias, conforme será retratado no capítulo posterior.
} 
universal, onde o ser humano retorne a ser o centro, onde se refute as mais diversas formas de guerra, onde a referência seja o bem comum e a não violência esteja presente em todas as relações do EU com o OUTRO.

Faz-se imprescindível a adoção de medidas para propiciar o fácil acesso à população mundial a eventuais invenções industrializáveis de remédios e vacinas contra pandemias em contraposição aos interesses comerciais das patentes instituídas sobre esses produtos sanitários. Essa garantia do acesso à saúde contra pandemias deve também ser fiscalizada e proporcionada pelos governos nacionais em consonância com o mínimo existencial, por ser ele um princípio norteador dos direitos sociais, demandando ações positivas para implementar os recursos indispensáveis para uma vida humana digna, à luz da Fraternidade (BAHIA, 2017, p. 219).

\section{Do direito à saúde e as novas tecnologias no enfrentamento de pandemias}

O surgimento de novas e temidas doenças é um acontecimento inerente à história da humanidade. Em maior ou menor grau, sempre surgiram e sempre advirão enfermidades imprevisíveis as quais, não raras vezes, ganharão proporções mundiais, enquadrando-se na gravidade de pandemias. ${ }^{6}$ Assim ocorreu em muitas circunstâncias, tais como a peste negra, gripe espanhola, tuberculose, síndrome de imunodeficiência adquirida (SIDA) e ebola, gerando constantes avaliações e tentativas de prevenção mundial (WORLD HEALTH ORGANIZATION, 2018).

Esse inconveniente e constante surgimento de calamidades sanitárias traz a necessidade proeminente de invenção de novas descobertas tecnológicas, especialmente remédios e vacinas, tanto subsidiadas pelos governos pátrios, como através da iniciativa privada nas universidades, laboratórios e indústrias farmacêuticas. Contudo, infelizmente essas inovações, além de serem normalmente dispendiosas, demandam tempo para a comprovação da eficácia dos experimentos, de modo que não raras vezes os seus patrocinadores requerem a respectiva proteção legal denominada patente, subespécie de propriedade industrial, a qual é reconhecidas a nível internacional por parte da Organização Mundial do Comércio (CONGRESSO INTERNACIONAL DE DIREITO E CONTEMPORANEIDADE, 2019, p. 07).

\footnotetext{
${ }^{6}$ Frise-se por oportuno que endemia se trata de qualquer doença incidente em espaço limitado, não se propagando para outras comunidades, ao passo que epidemia tem por característica a possibilidade de se espalhar para âmbitos externos. Já pandemia é um tipo mais grave de epidemia que pode se irradiar por vários continentes ou até para o mundo todo, como no caso da COVID-19 (LEITE; COSTA, 2020);
} 
Podemos ver como estes "novos" acontecimentos colocam em xeque a "humanidade" da Humanidade, onde os tradicionalmente excluídos se tornam ainda mais vulneráveis. Por isso, é necessário pensar no direito à saúde vinculado à noção de democracia, ou seja, as mais novas tecnologias devem estar ao alcance de todos, onde não podemos aceitar a privatização do conhecimento, de novas tecnologias. Viver em sociedade significa viver com o outro. A pandemia desvela a nossa falta de "viver com o outro", porém pode ao mesmo tempo desvelar o seu oposto, onde a fraternidade retorna.

Pode-se denominar por propriedade industrial como o conjunto de direitos concernentes a obras científicas, literárias, artísticas, invenções da atividade humana, descobertas científicas, desenhos, modelos industriais, marcas industriais, comerciais e de serviços, firmas e denominações comerciais, entre outras garantias inerentes à atividade intelectual. Nesse ínterim, o direito de propriedade industrial abarca o de patente, o qual se escoima pela concessão pelo Poder Público de um título de propriedade temporário aos inventores ou aperfeiçoadores de novos produtos ou processos os quais gozem de aplicabilidade industrial, garantindo aos seus titulares o direito de exclusividade e o retorno financeiro dos investimentos aplicados, garantida pela Organização Mundial da Propriedade Industrial (ESTOCOLMO, 2002). Partindo dessa diretriz, verificamos que tanto a propriedade industrial quanto a patente possuem a natureza jurídica de direito de propriedade, isto é, conferem ao titular as prerrogativas de usar (servir-se do direito), gozar (percepção dos frutos) e dispor (alienar, doar, consumir e vender), ou seja, inclui-se também na pauta da Declaração Universal dos Direitos Humanos, prevista no seu artigo XVII (CONFEDERAÇÃO NACIONAL DA INDÚSTRIA, 2013, pp. 17-21).

De se acrescentar que o patenteamento da descoberta de novas vacinas gera muitos benefícios não só para seus inventores, mas também para a sociedade em geral, visto que se presta a estimular novos métodos de produção, incentiva a pesquisa, melhora a qualidade de vida, coíbe fraudes contra o consumidor, impele o investimento em capital humano e intelectual, incrementa a qualidade de vida da população e favorece o comércio internacional. (CONFEDERAÇÃO NACIONAL DA INDÚSTRIA, 2013, p. 34) A nível internacional, os principais ordenamentos que protegem a propriedade industrial de fármacos são a Convenção da União de Paris (CUP) e o acordo Trade Related Aspects of Intellectual Rights (TRIPs), instituidores da Organização Mundial de Saúde (OMS) e da Organização Mundial do Comércio (OMC), respectivamente. (MELO e PAULO, 2012)

Conquanto o direito de propriedade industrial se configure como um direito fundamental e possua suas devidas funcionalidades, tal prerrogativa jamais deve ser vista de 
forma absoluta, mas sim em consonância com sua função social. Desse modo, em se tratando de doenças graves que extrapolem limites internacionais como no caso da COVID-19 e que demandem com urgência uma invenção e produção em larga escala de remédios e vacinas com vistas a evitar uma catástrofe pandêmica ainda mais perniciosa, esse direito deve ser relativizado em prol de outro direito fundamental: o direito à saúde, o qual deve prevalecer sobre o de propriedade industrial em tais casos, mesmo porque o primeiro está intimamente vinculado à dignidade da pessoa humana, que se constitui como núcleo insofismável da DUDH, prevista logo em seu preâmbulo.

A ponderação entre os dois direitos humanos em tela deve se pautar por cuidadosos critérios de razoabilidade e proporcionalidade e de forma consentânea com o princípio da fraternidade universal. Dito de outro modo, em situações onde houver urgente necessidade de acesso a vacinas e medicamentos contra pandemias que ameacem a população de forma a causar iminentes prejuízos em todos os setores da saúde pública mundial, deve-se afastar o direito de propriedade industrial sobre esses insumos farmacêuticos de modo a otimizar o acesso dos cidadãos, especialmente em se tratando de países pobres nos quais larga porção da população vive em condições precárias de higiene e saneamento básico.

Para se atingir esse intento, se faz também haver uma profícua interlocução entre as nações do Globo, preferencialmente através da via diplomática, envolvendo não só os governos, mas as populações envolvidas no sentido de se buscar compatibilizar os interesses comerciais e econômicos de laboratórios e indústrias farmacêuticas com o direito à saúde pública, superando inclusive as práticas protecionistas de países desenvolvidos industrializados pela contínua cooperação por meio de diálogos interinstitucionais. (MACHADO; MARTINI, 2018, p. 787)

Com efeito, baseados na premissa de que a saúde deve ser priorizada relativizando o direito de propriedade industrial, devem os Estados soberanos buscar garantir o acesso de todo e qualquer cidadão a remédios e vacinas contra pandemias de elevado nível de risco, como no caso da COVID-19, dentro da lógica de se promover o mínimo existencial e sempre com o sopesamento da reserva do possível, podendo-se buscar o proferimento de decisões favoráveis à chamada "quebra de patentes", coadunando-se os interesses privados das indústrias e laboratórios farmacêuticos com a função social da propriedade industrial. (MELO; PAULO, 2012)

Essa exigência é verificada também em virtude do que se chama de eficácia horizontal dos direitos fundamentais, já que, para a efetivação desses direitos, não se deve exigir somente 
um comportamento por parte do Poder Público (eficácia vertical), mas também a conscientização e participação de toda a sociedade, conforme o magistério de Clara Machado:

Em relação aos direitos fundamentais transindividuais, reconhece-se o correlato dever
de proteção a eles que abrange tanto o Estado (eficácia vertical) quanto os indivíduos
(eficácia horizontal), uma vez que, somente a partir da corresponsabilidade, é que os
direitos fundamentais transindividuais alcançarão sua máxima efetividade. Por
estarem ligados ao princípio da fraternidade, tais deveres serão denominados de
deveres de fraternidade. Os deveres de fraternidade impõem aos indivíduos e às
pessoas jurídicas de direito público e privado, com a devida proporção, a obrigação
jurídica de proteger direitos fundamentais transindividuais, a exemplo do meio
ambiente, desenvolvimento, paz, patrimônio cultural, gerando assim uma
corresponsabilidade social. Indubitavelmente, tanto o Estado quanto o indivíduo são
responsáveis por esses direitos e, somente com a cooperação de ambos
(corresponsabilidade), é que se viabilizará a sua máxima efetividade. (MACHADO,
2016, p. 150).

É nesse sentido que se passa a conceber a noção de "Constitucionalismo Fraternal", pelo qual a dimensão do princípio da fraternidade não é vista como algo isolado, mas sim permeando as franquias liberais e sociais de cada povo soberano, mediante a cobrança de ações estatais afirmativas, ora por meios administrativos, ora via medidas judiciais, a exemplo do caso brasileiro da chamada arguição de descumprimento de preceito fundamental. (FONSECA, 2019, p. 69).

Caso necessário, essas patentes podem ser "quebradas" também de forma extrajudicial, tanto para diminuir o preço dos insumos farmacêuticos quanto para desburocratizar a sua aquisição pelos governos e distribuidoras privadas ao redor do mundo, evitando intermináveis demandas judiciais que assoberbam o Poder Judiciário interno dos diversos países, bem como órgãos jurisdicionais internacionais, como o Órgão de Solução de Controvérsias da OMC. Por conta disso, a mediação administrativa, ao invés da judicialização, traduz-se como um instrumento decisivo na concretização do direito à saúde para o acesso a remédios e vacinas em pandemias atuais e futuras, com o intuito de estabelecer compromissos e transações. (MACHADO; MARTINI, 2018, p. 788). O fato é que, seja através de acordos internacionais, seja perante as cortes judiciais, seja através da desjudicialização (mediação/transação), as decisões em tais circunstâncias devem priorizar sempre o direito fundamental da saúde pública relativizando a propriedade privada industrial, sob pena de se malferir um outro princípio relativo aos direitos humanos de aspecto social: o da vedação do retrocesso.

Não se pode jamais olvidar também da necessidade, especialmente em países pobres, subdesenvolvidos e pouco industrializados, de seus governos envidarem mais esforços no sentido de investir em ciência e tecnologia para promoverem novas descobertas científicas e capacitarem de forma satisfatória seus profissionais da saúde, de modo a obterem de forma mais 
barata e acessível medicamentos e vacinas contra a COVID-19 e outras futuras pandemias graves, inclusive por meio de parcerias público privadas, a exemplo do que já prescreve o regulamento $n^{\circ} 557 / 2014$ do Conselho da União Europeia. Tais medidas indubitavelmente iriam baratear os custos de aquisição para a população, evitando os entraves financeiros e burocráticos da importação desses insumos, mesmo porque os debates a respeito da biotecnologia a partir do pressuposto da ética dizem respeito diretamente aos direitos humanos de quarta dimensão. (FONSECA, 2019, p.69).

Cabe também ao Poder Público, auxiliado pela população de consumidores, exigir dessas empresas que sejam criados remédios e vacinas em sintonia com uma criteriosa política de compliance $^{7}$, no sentido de serem evitados efeitos colaterais indesejáveis advindos da utilização contínua desses insumos, devendo-se primar não só pela cura ou prevenção das enfermidades, mas também pela satisfatória qualidade dos tratamentos.

\section{Da fraternidade como elemento integrador dos povos e nações em meio a graves pandemias}

Seguindo a lógica de que a saúde se configura na condição de direito humano expoente e de que a descoberta de novas tecnologias voltadas para pandemias mundiais deve ser tratada de forma universal, faz-se imprescindível levar em consideração que a fraternidade, na condição de direito de terceira dimensão, deve ser peremptoriamente valorada enquanto grande elemento norteador e integrador dos beneplácitos da profilaxia e tratamento mediante insumos farmacêuticos porventura engendrados. Infere-se, portanto, que as ações devem estar voltadas denotadamente para a criação de uma nova cultura mundial, geradora de um neoconstitucionalismo em cada nação soberana em harmonia com a legislação internacional, aplicando-se também o princípio da máxima efetividade, onde a saúde e a fraternidade devem ser priorizadas nas relações entre os países e mesmo nas relações privadas independentemente de diferenças de qualquer naipe. (MACHADO, 2007, pp. 01-03).

Essa nova cultura mundial deve primar de forma preponderante pela concretização do direito à saúde, não como um objetivo quimérico, mas uma realidade factível, na medida que, muito embora a maioria das legislações sejam bastante avançadas do ponto de vista teórico, muito ainda deixam a desejar na aplicabilidade prática. O surgimento de pandemias mundiais

\footnotetext{
7 Segundo CANDELORO, RIZZO e PINHO (2012, p.30) compliance "é um conjunto de regras, padrões, procedimentos éticos e legais, que, uma vez definido e implantado, será a linha mestra que orientará o comportamento da instituição no mercado em que atua, bem como a atitude dos seus funcionários".
} 
como a COVID-19 mostra que muito ainda se tem a progredir na busca pela efetivação dos direitos humanos de forma integrada ente as nações, de modo que o princípio da fraternidade exerce um papel decisivo e primordial nesse sentido. Essa relação inexorável entre a fraternidade e o direito à saúde universal é otimizada por um denominador comum, que é a dignidade da pessoa humana, a qual serve de pilar para a integração universal:

\begin{abstract}
Decerto, há, no princípio da fraternidade, a ideia originária da dignidade uma vez que a fraternidade está integrada ao reconhecimento da condição humana, de maneira que, ao praticar o ato fraterno, também se pratica um ato digno. Diante do conteúdo jurídico da fraternidade, os intérpretes do direito devem atualizar o sentido de comunidade política e democrática integrado ao aspecto específico da dignidade humana no viés constitucional.

A ordem constitucional fraterna ocupa um processo sociojurídico de adequação de sentido da dignidade, dado que a dignidade humana, enquanto experiência originária e fundante é elemento direcionador e estruturador da fraternidade.

(...)

Não bastasse isso, a fraternidade expande o imaginário da tradição moderna individualista ao direcionar o aspecto intersubjetivo da consciência fraterna na esfera do reconhecimento social. Assim sendo, a consagração jurídica da fraternidade numa sociedade plural e multidimensional intensifica o respeito pela dignidade humana assim como o conteúdo jurídico da dignidade repercute na razão fraterna ao direcionar o movimento dialético em meio às consciências individuais e sociais. (RESTA, MACHADO; MARTINI, 2017, pp.99-100).
\end{abstract}

Dito isto, subentende-se que a construção de um novo mundo pautado pela cooperação dos povos para vencer desafios que põem em xeque a saúde pública mundial deve ser guiada pelo crescimento e colaboração multicultural pela qual deve ser (re) lembrado o esquecido princípio da fraternidade juntamente com aqueles que nortearam a construção dos Estados Democráticos de Direito: liberdade e igualdade. (BARZOTTO; MARTINS; CORREIA, 2018, p. 168).

A transformação das sociedades convencionais para uma comunidade universal fraterna traduz um portfólio de funções nas mais variadas esferas: i) esfera ético-cultural, na incansável busca e difusão da verdade científica, fática, artística, ética e religiosa; ii) esfera política, visando o bem comum; iii) esfera jurídica, garantindo as expectativas legítimas da comunidade; iv) esfera econômica, pela partilha dos bens e serviços para satisfazer carências humanas, incluindo prevenção e cura de doenças pandêmicas. (BARZOTTO, 2018, pp. 43-44).

Portanto, no entrelaçamento entre as três dimensões dos Direitos Humanos, a fraternidade se presta como ponto integrador entre o princípio da liberdade (usar, gozar e dispor da propriedade industrial de remédios e vacinas) e o da igualdade (acesso isonômico à saúde pública por todos os povos em meio a pandemias graves). Direito e Política devem sempre caminhar lado a lado e a virtude está justamente no meio (medius in virtus), possibilitando a concretização de ações afirmativas direcionadas à saúde. (FONSECA, 2019, p. 72). 


\section{Conclusão}

A necessidade de se universalizar o acesso a novas tecnologias contra pandemias graves com base no princípio da fraternidade funda-se também na circunstância de que o direito à saúde, enquanto direito humano de imperiosa relevância, dispõe de uma contínua ampliação do alcance de seu conteúdo, o qual deve ser devidamente adequado para abarcar empecilhos decorrentes de pandemias graves ainda por vir no futuro, a exemplo da COVID-19.

As especulações comerciais e econômicas atinentes às descobertas tecnológicas de indústrias farmacêuticas e laboratórios não devem jamais estar alijadas da função social da propriedade industrial, de modo a serem interpretadas em consonância com a saúde pública, enquanto garantia universal, pautadas pelo princípio da Fraternidade, na condição de elemento integrador das nações.

Por conta dessas nuanças, defendemos com o máximo de urgência que sejam criadas normas no âmbito de organismos internacionais como ONU, OMS e OMC com o ímpeto de flexibilizar a exclusividade de patentes industriais relativas a fármacos e vacinas em se tratando de pandemias que ponham em colapso a saúde pública mundial, a exemplo da causada pelo “coronavírus".

Essa proteção internacional deve ganhar especial atenção no que tange aos grupos hipervulneráveis a pandemias vindouras, a exemplo de crianças, idosos, indígenas, cidadãos com deficiência, comunidades pobres e carentes (especialmente na África e América Latina) e portadores de doenças crônicas mais propensos a enfermidades graves (diabetes, AIDS, cardiopatias, doenças renais, bronquite asmática, entre outros), de forma a utilizar a Fraternidade como arauto desvelador de paradoxos, superando preconceitos contra essas classes hipossuficientes, por meio da promoção não só da eficácia vertical e horizontal dos direitos humanos, mas também da eficácia diagonal, fazendo valer de fato a isonomia material.

Crises sanitárias mundiais como a COVID-19 fazem-nos refletir acerca da impostergável necessidade de se pôr em prática uma acepção inovadora do Direito Internacional dos Direitos Humanos, pautada não só pela igualdade e liberdade individualista, mas também pela fraternidade, produzindo uma sociedade global verdadeiramente justa e inclusiva. 


\section{REFERÊNCIAS}

BAHIA, Flavia. Direito Constitucional. $3^{\text {a }}$ ed. coord: Sabrina Dourado. Recife: Armador, 2017.

BARBOSA, Marciane da Silva. O direito fundamental à saúde e o domínio comercial. Revista âmbito jurídico. São Paulo, ano XX, n. 163, ago. 2017. Disponível em:

$<$ https://ambitojuridico.com.br/cadernos/direito-constitucional/o-direito-fundamental-a-saudee-o-dominio-comercial/>. Acesso em 28 mai. 2020

BARZOTTO, Luciane Cardoso; MARTINS, Renata Duval e CORREIA, Carolina Simões. Fraternidade e justiça social: imigração na constituição brasileira de 1988 e na convenção 143 da OIT. In: BARZOTTO, L. F. et al. (org.) Direito e Fraternidade: outras questões. Porto Alegre: Sapiens, 2018.

BARZOTTO, L. F.. Sociedade fraterna. In: BARZOTTO, L. F. et al. (org.) Direito e Fraternidade: outras questões. Porto Alegre: Sapiens, 2018.

BRASIL Ministério da Saúde. Agência Nacional de Saúde Suplementar (ANS). Promoção da saúde e prevenção de riscos e doenças na saúde suplementar: manual técnico. $2^{\mathrm{a}}$ ed. Rio de Janeiro : ANS, 2007.

BRASIL Ministério da Saúde. Resolução GMC n 151/96. Brasília, 2014. Disponível em: $<$ http://www.saude.gov.br/images/pdf/2014/marco/10/resolucaogmc151de96.pdf $>$. Acesso em 28 mai. 2020.

CANDELORO, Ana Paula P.; RIZZO, Maria B. M. de; PINHO, Vinícius. Compliance 360: riscos, estratégias, conflitos e vaidades no mundo corporativo. São Paulo: Trevisan Editora Universitária, 2012.

CONFEDERAÇÃO NACIONAL DA INDÚSTRIA. CNI. Propriedade industrial aplicada: reflexões para o magistrado. - Brasília: CNI, 2013.

CONGRESSO INTERNACIONAL DE DIREITO E CONTEMPORANEIDADE. 5, 2019. Santa Maria/RS. O instituto das patentes e o acesso a medicamentos: uma análise a partir da função social da propriedade industrial. Santa Maria: UFSM, 2019.

PORTAL EDUCAÇÃO. Promoção da saúde: contexto histórico. Disponível em: $<$ https://www.portaleducacao.com.br/conteudo/artigos/direito/promocao-da-saude-contextohistorico/13463>. Acesso em 16 jun. 2020.

ESTOCOLMO. Convenção que institui a Organização Mundial da Propriedade Intelectual. Assinada em Estocolmo em 14 de Julho de 1967, e modificada em 28 de Setembro de 1979. Genebra, 2002. Disponível em:

$<$ https://www.wipo.int/edocs/pubdocs/pt/wipo_pub_250.pdf.> Acesso em 31 maio de 2020.

FONSECA, Reynaldo Soares da. O princípio jurídico da fraternidade no Brasil: em busca de concretização. Revista dos Estudantes de Direito da Universidade de Brasília - n. 16 Brasília: RED|UnB, 2019. 
LEITE, Gisele; COSTA, Arthur Rioboo da. Consequências jurídicas do coronavírus (covid-19). Porto Alegre, 2020. 2014. Disponível

em: $<$ http://www.lexmagister.com.br/doutrina_28008441_consequencias_juridicas_do_corona virus_covid_19.aspx $>$. Acesso em 28 mai. 2020.

MACHADO, Clara. A fraternidade no direito constitucional brasileiro: um instrumento para proteção de direitos fundamentais transindividuais. 2016. 204 f. Tese (Doutorado em Direito Público) - Universidade Federal da Bahia, Salvador 2016.

MACHADO, Clara. O neoconstitucionalismo e a aplicação imediata dos direitos fundamentais nas relações privadas. Revista Direitos Fundamentais \& Democracia, v. 2, n. 2, ISSN 1982-0496, Curitiba, 2007.

MACHADO, Clara; MARTINI, Sandra Regina. Desjudicialização da saúde, diálogos interinstitucionais e participação social: em busca de alternativas para o sistema. Revista Estudos Institucionais, v. 4- n. 2, 2018.

MARTINI, Sandra Regina. Saúde: um direito fundado na fraternidade. In: Fundação Oswaldo Cruz, Núcleo de Estudos em Direitos Humanos e Saúde Helena Besserman. Saúde e direitos humanos, ano 5, n. 5 (2008). Brasília: Editora do Ministério da Saúde, 2009.

MELO, Milena Barbosa de; PAULO, Christiane Ramos Barbosa de. O desequilíbrio entre a função social das patentes de medicamentos e o interesse individual das empresas farmacêuticas. Revista âmbito jurídico. São Paulo, ano XIII, n. 98, mar. 2012. Disponível em: $<$ https://ambitojuridico.com.br/edicoes/revista-98/o-desequilibrio-entre-a-funcao-socialdas-patentes-de-medicamentos-e-o-interesse-individual-das-empresas-farmaceuticas/> Acesso em 01 jun. 2020.

RAMOS, André de Carvalho. Curso de direitos humanos. $7^{\text {a }}$ ed. São Paulo: Saraiva, 2020.

RAMOS, André Luiz Santa Cruz. Direito empresarial esquematizado. $4^{\mathrm{a}}$ ed. Rio de Janeiro: Forense; São Paulo : Método, 2014.

RESTA, Eligio; MACHADO, Clara; MARTINI, Sandra Regina. Direito e Fraternidade: a dignidade humana como fundamento. Revista do Direito, v. 3, n. 53, set./dez. 2017. Santa Cruz do Sul: UNISC, 2017.

STJ. HABEAS CORPUS No 563.142 - SE (2020/0044621-5) Relator : Ministro Reynaldo Soares da Fonseca. DJ: 19/03/2020. STJ, 2020. Disponível em:

$<$ https://scon.stj.jus.br/scon/decisoes/toc.jsp?livre $=563.142 \&$ processo $=563142$. num. $\& b=\mathrm{dtxt}$ $\&$ thesaurus $=$ juridico $\& p=$ true $\#$ doc $2>$. Acesso em 29 mai. 2020.

UNIÃO EUROPEIA. Decisão $\mathbf{n}^{0}$ 1082/2013/EU do parlamento europeu e do conselho. 22 out. 2013. Disponível em: <https://eur-lex.europa.eu/legalcontent/PT/TXT/?uri=celex:32013D1082> Acesso em 28 mai. 2020.

VENTURA, Miriam. Direitos humanos e saúde: possibilidades e desafios. In: MINISTÉRIO DA SAÚDE. Fundação Oswaldo Cruz. Saúde e direitos humanos.- Ano 7, n. 7 (2010). - Rio de Janeiro: 2010. 
WORLD HEALTH ORGANIZATION. The top 10 causes of death. 24 mai. 2018.

Disponível em: $<$ https://www.who.int/news-room/fact-sheets/detail/the-top-10-causes-ofdeath $>$ Acesso em 29 mai. 2020. 